\title{
Reconciliation Rising: The Roles of the Everyday and the Informal in Successful Post- conflict Reconciliation ${ }^{1}$
}

\author{
Ivor Sokolić \\ London School of Economics and Political Science
}

\begin{abstract}
Post-conflict reconciliation has become a problematic concept due to the expectation that its success entails formerly opposed groups coming to terms with the past and building a shared identity between them. This is usually achieved through controlled and designed efforts to force inter-ethnic interaction. These are seen as artificial and imposed by the intended beneficiaries of the process and are subsequently rejected. The articles in this special section reveal these challenges and disrupt our understanding of what successful reconciliation looks like. They do so by examining interethnic interaction at different levels and in different realms: the micro and the macro; the formal and the informal; the individual and the societal. The special section asks: what types of interethnic interaction facilitate reconciliation? How do interactions at one level affect other levels? And, how can these interactions be studied? The papers show that successful effects of reconciliation can move from the bottom up; that formal institutions and elite actors can hinder reconciliation; and, that qualitative ethnographically sensible methodologies effectively capture these effects and take into account the specificity of reconciliation processes.
\end{abstract}

\footnotetext{
${ }^{1}$ Ivor Sokolić gratefully acknowledges the support received from the Arts and Humanities Research Council PACCS 'Art and Reconciliation: Culture, Community and Conflict' (AH/P005365/1) project grant.
} 
Post-conflict reconciliation is a problematic concept for practitioners, academics and intended beneficiaries of the process. It is loaded with normative expectations of what the process ought to look like, which hampers both academic analyses and implementation of reconciliation efforts. The effect is that scholars cannot agree on what constitutes success in the realm and local publics reject the concept. Mainstream approaches focus on discourses and narratives as drivers or obstacles to reconciliation. They often aim to create shared identities or understandings of the past and view reconciliation as an end product. Many of these efforts are subsequently viewed as artificial and imposed by external actors. Methodologically the concept is difficult to measure because it is not linear and it occurs across different levels, often simultaneously.

The articles in this special section expose these challenges and disrupt our understandings of what reconciliation looks like. They do so by examining interethnic interactions at the micro and the macro levels; in the realms of the formal and the informal; and, between individuals and society. The papers go beyond an understanding of these levels as distinct from each other, instead they attempt to explain how the effects of reconciliation move from one level to another. The special section asks: what types of interethnic interaction facilitates reconciliation? How do interactions at one level affect other levels? And, how can these interactions be studied? The articles remove expectations of what reconciliation should look like, they highlight the dangers of artificiality in processes of reconciliation and they highlight the advantages of ethnographically sensible approaches in this field of study (Simmons and Rush Smith, 2017).

This type of approach has already been implicitly written into much of the scholarship on reconciliation, peacebuilding and transitional justice. Various disciplinary approaches all examine the same concept. Their lack of a unified vocabulary or comparative framework highlights the specificity of reconciliatory processes. Farmaki (2017) argues that interaction through tourism holds latent, but not exclusive, capability to transform political, social and economic spheres. In Kosovo, such interactions have been observed in shopping centres and swimming pools (Fridman, 2015). Smyth and MacKnight (2013) shed light on coping strategies and behavioural norms in the post-conflict setting by looking at the everyday, routine interactions of mothers walking, shopping and playing with their children in Belfast. This is mirrored in Bosnia-Herzegovina, where Pickering looks at how ethnic groups interact in their neighbourhood, workplace, local government and other day to day settings (Pickering, 2007). 
The positive effects can be a by-product of more formal, reconciliation-focused, efforts. UN conflict resolutions workshops for Syrians were marked by the rejection of calls for reconciliation but they resulted in a functional cooperation between conflicted groups at the margins of the core interactions (Arai, 2013). Types of interactions matter and different interactions, as well as different participants, lead to different outcomes. Osborne, D'Exelle and Verschoor (2017) find that interactions affect social cohesion in the aftermath of conflict, especially for specific actors, such as former combatants. Quinn (2016) argues that inter-ethnic interaction develops "thin sympathy"; a basic understanding of the needs of the other.

Successful reconciliation can, therefore, be implicit since it occurs in efforts that intend to be reconciliatory, as well as those that do not, in both the formal and informal domains. Interactions may be improving interethnic relations and reducing prejudice, even in an apparent absence of reconciliation between groups. Such an interpretation of reconciliation is also embedded in process-oriented understandings of the process. According to Lederach, peace systems are characterised by interdependent relationships that can find non-violent mechanisms to resolve conflict (Lederach, 1997: 84). This lies at the heart of interactions that have a positive impact on intergroup relations. Lederach stresses the necessity for a framework of interconnected people and relationships, sustained over time and all levels of society, in order for groups to reconcile (ibid.). Interdependence can occur in the realms of culture, arts, politics, sports, trading and many others. Crucially, these realms are free of the normative load of reconciliation. There are no expectations associated with what these interactions ought to look like.

\section{Facilitating, Hindering and Studying Reconciliation}

The articles in this special issue highlight what types of interaction facilitate reconciliation, what types hinder the process and how qualitative, ethnically sensible methodologies are useful in the study of post-conflict reconciliation. Interaction across ethnic boundaries is common, despite a meta-context of societal division (Mac Ginty, 2014: 552). In a society marked by ethnic division, individuals still need to negotiate their way through a complex range of norms and practices that shape their understanding of the world around them (ibid.: 553). This special section shows that these interactions occur at all levels of society and that they result in ripple effects that transcend levels. Reconciliatory effects are not mechanistic and do not move in a 
single direction. Instead, they can happen at the everyday or elite level. They can also be rejected at one level or both. Effects move from the top-down or the bottom-up and the articles reflect this: Anne Brown examines the granular effects of face-to-face interactions in building trust, while Melanie Garson looks at how societal change can occur. They show that trickling up effects are crucial for reconciliation to be effective, even though most peacebuilding processes are evaluated based on their impact downwards. The authors show that one of the key challenges of reconciliation is to effectively move individual level transformation to the societal level; a process that remains undertheorized in the literature.

Embedded into this dynamic are both formal and informal processes that can aid or hamper reconciliation. Informal processes often occur at the everyday level and can aid reconciliation, while formal processes in the context of ethnically divided societies often hamper reconciliation. The papers highlight the importance of informal interactions for reconciliation: they can help the process start and they are crucial to the process' durability. Yet the formal and informal need to work in tandem, since one can undermine the other. Daniela Lai shows this in her examination of protests in Bosnia-Herzegovina, where cooperation across ethnic lines between ordinary citizens was hampered by elites who rely on ethnic division as a source of legitimacy. She shows that in Bosnia-Herzegovina, as well as elsewhere, informal intergroup interaction is demobilised by ruling elites through formal channels (Fridman, 2015; Hromadžić, 2015; Jansen, 2013; Mamdani, 1996; Touqet, 2015). The ripple effects of interaction and the role of informality result in an understanding of reconciliation as ambiguous, negotiated and political. Lai, drawing on Schaap (2008), argues that this contestation can be an inherent part of reconciliation. That contestation is laden with opportunity because it allows for inter-ethnic relations to be negotiated.

The authors agree that one particular factor hinders reconciliation efforts: artificiality. Interaction that requires trained professionals can seem artificial (Hughes, 2018). If administered by external actors or from the top-down, they can be seen as forced or imposed (Hodson \& Hewstone, 2013; Rosoux and Anstey, 2017). Brown stresses that imposing solutions or artificiality has negative consequences on trust. Lai praises informal interactions because they are unforced and spontaneous. Garson, who examines some of these controlled dialogue workshops, acknowledges that the true effect of the workshops occurs outside of the controlled and managed environment (echoing Arai, 2013). 
The special section speaks to the endogeneity and specificity of reconciliation. This is reflected in the methodological choices made by the authors. All take a single case study or small-N approach. Two focus on Bosnia-Herzegovina wholly (Lai) or largely (Garson). Brown examines several cases, but once again former Yugoslavia features. The authors show that the study of post-conflict societies and post-conflict reconciliation is complex and that controlled comparisons, which de-emphasize context, can diminish the relevance of contextual factors that are crucial. In processes as contested, undefined and complex as reconciliation, an approach that requires discrete and well-defined variables struggles to factor in the endogeneity of the process and mistakenly overestimates homogeneity across cases (Locke and Thelen, 1995). The articles in this special section exemplify the strength of qualitative research in providing contextualised understandings of political processes (Simmons and Rush Smith, 2017: 126). All of the articles, even if not strictly ethnographic, have an ethnographic sensibility in their analyses that takes into account how individuals enmeshed in reconciliation processes construct the world around them (Simmons and Rush Smith, 2017: 126).

\section{Observable Outcomes of Interaction}

The inter-ethnic interactions and ripple effects examined by the authors resulted in a range of positive outcomes that facilitate reconciliation. Four observable outcomes can be identified that occur, to a lesser or greater degree, across all cases. These are not exhaustive, and they do not occur in a uniform fashion, but they do point to the potential for such interactions to improve inter-ethnic relations. The outcomes are also not distinct, they are best conceptualised as a feedback loop in which all effects influence each other. They highlight that reconciliation is ambiguous, messy and not an end state, but rather a process (Lederach, 1997).

Socialisation: the interactions involve some form of socialisation or mixing between groups, no matter how elementary. This may involve physical mixing; learning about the symbols or norms of a different groups; or even adopting those norms.

Shared aspirations: some interactions were based on shared aspirations. For reconciliation to succeed, these need to be shared across members of different groups (for example, they may want to learn each other's languages or partake in dialogue programmes). 
Resistance: interactions with a reconciliatory outcome resist, overtly or covertly, divisive normative frameworks or inter-group boundaries.

Cooperation: individuals from conflicting groups may cooperate and work together during their interactions. This most likely involves socialisation and shared aspirations, but also goes beyond this by requiring individuals to cooperate with each other to achieve a shared goal or to employ symbols of another group for their own purposes.

\section{Empirical Examples}

The articles empirically explore the process through which inter-ethnic interactions can result in reconciliatory outcomes. They unpack the process and facilitating conditions that enable this to occur.

Lai uses the case study Bosnia-Herzegovina to highlight how certain interactions have unintended reconciliatory outcomes. She looks at whether and how civic protests can amount to reconciliation. She finds that mixing, resistance and shared aspirations can build civic solidary that transcends ethnic boundaries. Garson examines interactions that aim to have reconciliatory outcomes in Israel-Palestine and Bosnia-Herzegovina. The paper connects the individual level to the societal level, in order to better evaluate grassroots reconciliation initiatives. This helps us understand what conditions facilitate reconciliation at the societal level. Brown focuses specifically on face-to-face interactions but investigates both those with intended and unintended reconciliatory outcomes, within a framework that focuses on trust. The paper outlines several examples to show that there is a physical dimension to building trust that is often overlooked in accounts of reconciliation.

Collectively, these works make us question what reconciliation means and how its effects ripple from one level to another. They look at positive inter-group outcomes but conceptualise them, and therefore reconciliation, in different ways. To Lai, inter-ethnic interactions are positive when they result in civic solidarity, defined as "a forward-looking commitment to fighting for social justice and against the privileges of political elites" (Lai, this volume: 6). To Garson, positive outcomes are the formation of peace constituencies that help to maintain peace 
agreements. These peace constituencies are created by the trickling up of transformation, from individuals and small groups, to the societal level. To Brown, the positive outcome is trust between individuals. Trust does not involve shared identity, agreement or shared perspective, instead it allows for the recognition of difference, vulnerability and uncertainty, through which both collective and individual emotions can be negotiated.

This special section attempts move away from the normativity of reconciliation, which places certain expectations on the process and assumes that it occurs in a mechanistic and linear fashion. It highlights that successful reconciliation comes in many forms and that the process may already be occurring in societies, but that it may not take a uniform format across all cases. The articles show that positive inter-ethnic interaction at the level of the everyday and in the informal realm can ripple across a society and trickle up. Controlled attempts at reconciliation, on the other hand, are often rejected by the intended beneficiaries of the process since they seem artificial and imposed. Especially so in a context where institutional support is lacking and elite actors are incentivised to hinder the process, since they gain their legitimacy through ethnic division. In highlighting this, the articles also show that scholarly analyses and methodologies need to be attuned to the complexity of reconciliation processes, their ambiguity and their many conceptualisations. 


\section{References}

Arai, T. (2013) Syria in Search of a Political Solution: Toward Functional Coexistence. Transcend Media Service: Solutions-Oriented Peace Journalism. Available at: https://www.transcend.org/tms/2013/09/syria-in-search-of-a-political-solution-towardfunctional-coexistence/. Accessed on 12 April 2018.

Farmaki, A. (2017). The Tourism and Peace Nexus. Tourism Management, 59, 528-540.

Fridman, O. (2015). Unstructured Daily Encounters: Serbs in Kosovo after the 2008 Declaration of Independence. Contemporary Southeastern Europe (2)1: 173-190.

Hodson, G., \& Hewstone, M. (2013). Advances in Intergroup Contact. New York: Psychology Press.

Hromadžić, A. (2015). On Not Dating Just Anybody: The Politics and Poetics of Flirting in a Post-war City. Anthropological quarterly, 88(4), 881-906.

Hughes, J. (2018). Agency versus structure in reconciliation. Ethnic and Racial Studies, 41(4): 624-642.

Jansen, S. (2013). If Reconciliation is the Answer, Are We Asking the Right Questions?. Studies in Social Justice, 7(2), 229-243.

Lederach, J. P. (1997). Building Peace: Sustainable Reconciliation in Divided Societies,

Washington DC, United States Institute of Peace.

Locke, R., \& Thelen, K. (1995). Apples and Oranges Revisited: Contextualized Comparisons and the Study of Comparative Labor Politics. Politics \& Society, 23(3), 337-367.

Mac Ginty, R. (2014). Everyday peace: Bottom-up and local agency in conflict-affected societies. Security Dialogue, 45(6), 548-564.

Mamdani, M. (1996). Reconciliation Without Justice. South African Review of Books, Issue 46, November/December 1996.

Osborne, M., D’Exelle, B., \& Verschoor, A. (2018). Truly reconciled? A dyadic analysis of post-conflict social reintegration in Northern Uganda. Journal of Peace Research, 55(1), 107-121.

Pickering, P. (2007) Peacebuilding in the Balkans: The view from the ground floor. Ithaca: Cornell University Press.

Quinn, J. (2016) Cultivating Sympathy and Reconciliation: The Importance of Sympathetic Response in the Uptake of Transitional Justice. In The limits of settler colonial reconciliation: Non-Indigenous people and the responsibility to engage, eds. Tom Clark, Ravi de Costa, Sarah Maddison. New York: Springer, 119-135. 
Rosoux, V. and Anstey, M. (2017) Negotiating reconciliation in peacemaking: Quandaries of relationship building. Springer.

Schaap, A. (2008). Reconciliation as ideology and politics. Constellations, 15(2), 249-264.

Simmons, E., \& Smith, N. (2017). Comparison with an Ethnographic Sensibility. 50(1), 126130.

Smyth, L. and McKnight, M. (2013) Maternal Situations: Sectarianism and Civility in a Divided City. The Sociological Review, 61, 304-322.

Touquet, H. (2015). Non-ethnic mobilisation in deeply divided societies, the case of the Sarajevo protests. Europe-Asia Studies, 67(3), 388-408. 